\title{
Premalignant gastric lesions in patients included in National colorectal cancer screening
}

\author{
${ }^{1}$ Abacus Medico, Diagnostic Center Rogaška, Rogaška Slatina, Slovenia \\ ${ }^{2}$ General Hospital Murska Sobota, Murska Sobota, Slovenia \\ ${ }^{3}$ General Hospital Slovenj Gradec, Slovenj Gradec, Slovenia \\ ${ }^{4}$ Diagnostic Center Bled, Bled, Slovenia \\ ${ }^{5}$ General Hospital Trbovlje, Trbovlje, Slovenia \\ ${ }^{6}$ MC Heliks, Trbovlje, Slovenia \\ ${ }^{7}$ MC Rogaška, Rogaška Slatina, Slovenia \\ 8 IMI, Faculty of Medicine, University of Ljubljana, Ljubljana, Slovenia
}

Bojan Tepes ${ }^{1}$, Maja Seruga², Miroslav Vujasinovic ${ }^{3}$, Dejan Urlep ${ }^{4}$, Liljana Ljepovic ${ }^{4}$, Jurecic Natasa Brglez ${ }^{5}$, Alenka Forte ${ }^{6}$, Ljubec Anita Kek ${ }^{7}$, Miha Skvarc ${ }^{8}$

Radiol Oncol 2018; 52(1): 7-13.

Received 11 September 2017

Accepted 10 October 2017

Correspondence to: Prof. Bojan Tepeš, M.D., Ph.D., FEBGH FSMA, AM DC Rogaška, Prvomajska 29 A, 3250 Rogaška Slatina, Slovenia; E-mail: bojan.tepes@siol.net

Disclosure: No conflicts of interest were disclosed.

Background. Gastric cancer is the fifth most common malignancy in the world with almost one million new cases annually. Helicobacter pylori infection causes $89 \%$ of all gastric cancers. Premalignant lesions (atrophy and intestinal metaplasia) develop after several decades of inflammation. Secondary prevention with gastroscopy is possible, but it is costly and has a low compliance rate. Alternative procedures like serology testing for pepsinogen I and II and pepsinogen I/II ratio are available to select patients for surveillance gastroscopies.

Patients and methods. In seven outpatient endoscopic units, 288 patients (154 men; 53.5\%), average age 60.68 years, tested positive in National colorectal cancer screening programme SVIT, were included in the study. Gastropanel (BioHit, Finland) was used as a serologic biopsy method.

Results. We found 24 patients (12 men, mean age 63.7 years) with pepsinogen (pepsinogen $1 / \|<3$ and/or pepsinogen I $<30 \mu \mathrm{g} / \mathrm{L}$ ). Premalignant changes were found on gastric biopsies in 21 patients $(7.3 \%$ incidence). Operative Link on Gastric Intestinal Metaplasia Assessment (OLGIM) $\geq 1$ was found in 20 patients; Operative Link for Gastritis Assessment (OLGA) $\geq 1$ was found in 19 patients. Combined accuracy for preneoplastic lesions in Gastropanel positive patients was $87.5 \%$. H. pylori seropositivity was found in 219 patients (76\%). Only $24 \%$ of our population had normal results.

Conclusions. Gastropanel test has proven to be a reliable non-invasive test for advanced gastric preneoplastic lesions that can select patients for further gastroscopy. We found high H. pylori seropositivity in older age groups in Slovenia.

Key words: gastropanel; Helicobacer pylori; atrophy; intestinal metaplasia; gastric cancer

\section{Introduction}

Gastric cancer (GC) remains the fifth most common malignancy with almost one million new cases annually and is responsible for $9 \%$ of all cancer related deaths in the world (third place). ${ }^{1}$
In Slovenia, the average incidence of gastric cancer in the period from 2009 to 2013 was 479 new cases of gastric cancer per year. The incidence rate was higher for men $(29.1 / 100,000)$ than for women $(17.8 / 100,000)$, with only $28 \%$ five-year survival rate. $^{2}$ 
Helicobacter pylori (H. pylori) is grade I carcinogen and responsible for $89 \%$ of all gastric cancers. ${ }^{3}$ Several decades of infection with H. Pylori can cause some preneoplastic changes, atrophy and intestinal metaplasia, in half of the infected patients. ${ }^{4}$ Primary gastric cancer prevention program would be a National screening program for H. pylori infection with eradication of those infected. Secondary gastric cancer prevention program would be possible if we could find patients with severe preneoplastic changes in the stomach and offer them regular upper gastrointestinal endoscopies. Population-based screening by endoscopy for detection of these preneoplastic lesions is not feasible, except in Japan and Korea.5,6 In Western countries, regular endoscopic follow-up is offered to patients with endoscopically visible preneoplastic lesions according to MAPS recommendations ${ }^{7,8}$, but this represents only opportunistic secondary prevention.

Serologic biopsy - measuring pepsinogen I and pepsinogen II (PGI, PGII), Gastrin 17 (G 17) and $H$. pylori antibodies in the serum can select those patients with preneoplastic gastric lesions. In case of corpus atrophy and intestinal metaplasia, the production of pepsinogen I goes down more than pepsinogen II, which is produced also in antrum. Gastropanel (Biohot Ojy, Finland) has set cut-off for corpus atrophy at PGI/PGII < 3 and/or PGI < $30 \mu \mathrm{g} / \mathrm{L})$.

If a patient is not on PPI therapy, increased Gastrin 17 can be another marker of low gastric acid secretion and corpus atrophy. Gastrin 17 is lower than normal in case of atrophy in antrum, or in case of gastric hypersecretion. ${ }^{9} \mathrm{H}$. pylori seropositivity is a risk factor for gastric cancer and up to $2.9 \%$ of infected patients can develop gastric cancer in their lifetime. ${ }^{10}$

Serologic biopsy is more accurate in the diagnosis of corpus atrophic gastritis (CAG) than antral atrophic gastritis (AAG) with $70.2 \%$ vs. $51.6 \%$ pooled sensitivity and $93.9 \%$ vs. $84.1 \%$ pooled specificity. ${ }^{11}$ The serologic biopsy can be of help in finding those patients in the population who have advanced premalignant gastric lesions. This method is already used in Japan, China and Finland. ${ }^{12-15}$

In our multicenter prospective study, we wanted to assess the accuracy of serologic biopsy (Gastropanel) in the diagnosis of premalignant gastric lesions (primary objective of the study) as well as the prevalence of $\mathrm{H}$. pylori infection (secondary objective of the study) in a population of patients included in a National colorectal cancer screening program (age 50 to 74 years) who are FIT positive and thus referred to coloscopy.

\section{Patients and methods}

Patients included in the National colorectal cancer screening, tested FIT positive, and scheduled for screening colonoscopy in seven outpatient endoscopic units were invited to participate in the study. Exclusion criteria were use of PPI or $\mathrm{H} 2$ blockers in the previous two weeks. Those that fulfilled the criteria and signed the Informed Consent Statement were included.

Fasting serum with EDTA $(2 \times 5 \mathrm{ml})$ were frozen to $-20^{\circ} \mathrm{C}$ and transported on dry ice to Central laboratory at the Institute for Microbiology and Immunology at the Medical Faculty in Ljubljana, where it was frozen and stored at $-80^{\circ} \mathrm{C}$. Byohit Elisa test was used for PGI and PGII, G 17, and anti-H. pylori antibodies (IgG-Hp). According to producer data, normal values are: PGI 30-165 $\mu \mathrm{g} / \mathrm{L}$,

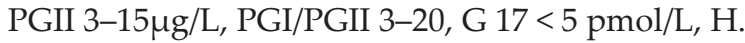
pylori antibodies $<30$ EIU. If PGI/PGII was $<3$ and/ or PGI $<30 \mu \mathrm{g} / \mathrm{L}$, patients were invited to upper gastrointestinal endoscopy. ${ }^{16,17}$

Five biopsies (two from the lower and upper curvature $3 \mathrm{~cm}$ from the pylorus, one from incisura angularis, and two from lower and upper curvature of middle corpus) and two biopsies (from antrum and corpus) for rapid urease test (RUT) were taken. According to updated Sydney protocol and Operative Link for Gastritis Assessment (OLGA) / Operative Link on Gastric Intestinal Metaplasia Assessment (OLGIM) classification, the histopathological analysis was performed by expert gastrointestinal pathologist. ${ }^{18-20}$

Patients who were $\mathrm{H}$. pylori positive (positive anti-H. pylori antibodies or histology) and have normal pepsinogen levels took the urea breath test; according to national recommendations. If the result was positive, they received a 7-day triple regimen. ${ }^{21}$

The primary objective of the study was to detect patients with preneoplastic conditions (i.e. atrophic gastritis/intestinal metaplasia) in stomachs of fecal immunochemical test (FIT) positive patients included in National colorectal cancer screening with serologic biopsiy (GastroPanel ${ }^{\circledR}$, Byohit, Helsinki, Finland).

The secondary objective of the study was to determine the prevalence of $\mathrm{H}$. pylori infection in the age group from 50 to 74 years. 
TABLE 1. Demographic data of patients included

\begin{tabular}{lcc}
\hline Patients & Number & Percentage \\
\hline Men & 154 & $53.5 \%$ \\
Women & 134 & $46,5 \%$ \\
Total & 288 & $100 \%$ \\
$50-60$ years & 134 & 46.5 \\
$61-70$ years & 120 & 41.7 \\
$70+$ & 34 & 11.8 \\
\hline
\end{tabular}

\section{Statistical analysis}

The results of the Gastropanel testing (in Excel format) were submitted to Biohit Oyj (Helsinki, Finland) for final analysis using the GastroSoft ${ }^{\circledR}$ (Biohit Oyj) interpretation software. ${ }^{16,22}$ All statistical analyses were performed using the SPSS 23.0.0.2 for Windows (IBM, Armonk, NY, USA) and STATA/SE 14.1 software (Stata Corp., College Station, TX, USA). Frequency tables were analyzed using the Chi-square test, with likelihood ratio (LR) or Fischer's exact test being used to assess the significance levels between the categorical variables. Using the exact method, odds ratios (OR) and their $95 \%$ confidence intervals $(95 \% \mathrm{CI}$ ) were calculated where appropriate. Differences in the means of continuous variables were analyzed using the nonparametric tests (Mann-Whitney, Kruskal-Wallis), with the mean $(95 \% \mathrm{CI})$ values being derived from analysis of variance (ANOVA).

\section{Ethics}

The study was registered at the National Ethical Committee of the Ministry of Health under number 158/07/13 and was conducted in accordance with the Declaration of Helsinki, consistent with Good Clinical Practices recommendations.

\section{Results}

In seven SVIT endoscopic units, 288 patients, 154 men $(53.5 \%)$ and 134 women $(46.6 \%)$, average age 60.68 years (from $50-75$ ), were included (Table 1 ). Results of Gastropanel for different age groups and sex are shown in Tables 2 and 3.

After data (in Excel) have been processed by using the GastroSoft ${ }^{\circledR}$ (Biohit Oyj) interpretation software, 4 different phenotypes of gastric histology by serologic biopsies (Gastropanel) have been found (normal Gastropanel, H. pylori gastritis,

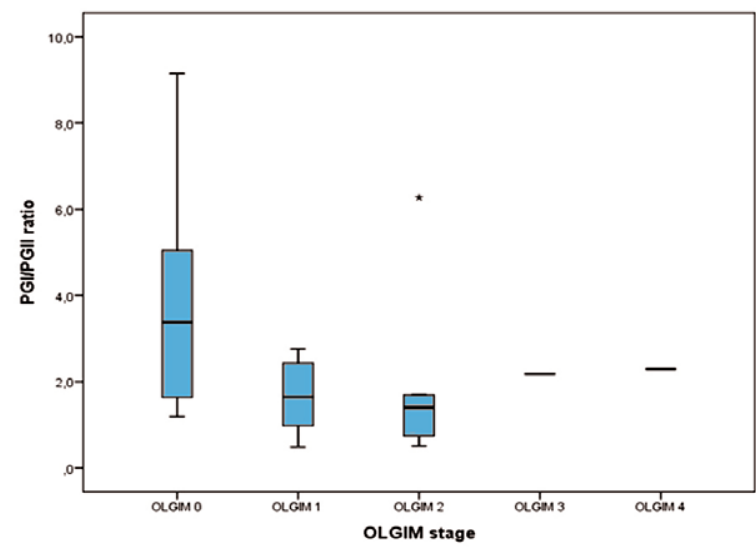

FIGURE 1. Prostaglandin I (PGI) / Prostaglandin II (PGII) ratio according to Operative Link on Gastric Intestinal Metaplasia Assessment (OLGIM) stage.

Corpus atrophic gastritis, Antrum atrophic gastritis) (Table 4).

Only $24 \%$ of our population had a normal Gastropanel test (no premalignant lesions and

TABLE 2. Gastropanel data for different age groups

\begin{tabular}{|c|c|c|c|c|c|}
\hline & Age range & $\mathbf{N}$ & Mean & $\begin{array}{c}\text { Std. } \\
\text { Deviation }\end{array}$ & $\begin{array}{l}\text { Std. } \\
\text { Error }\end{array}$ \\
\hline \multirow[t]{4}{*}{$\begin{array}{l}\text { G } 17 \text { basal } \\
\text { (pmol/L) }\end{array}$} & $50-59$ years & 105 & 7.1860 & 8.6474 & 0.8439 \\
\hline & 60-69 years & 99 & 17.8350 & 99.0131 & 9.9512 \\
\hline & $70+$ years & 32 & 8.9800 & 10.7870 & 1.9069 \\
\hline & Total & 236 & 11.8970 & 64.5188 & 4.1998 \\
\hline \multirow[t]{4}{*}{ PGI $(\mu \mathrm{g} / \mathrm{L})$} & $50-59$ years & 134 & 95.9870 & 42.1806 & 3.6438 \\
\hline & $60-69$ years & 120 & 97.9820 & 42.5086 & 3.8805 \\
\hline & $70+$ years & 34 & 87.4010 & 53.5304 & 9.1804 \\
\hline & Total & 288 & 95.8050 & 43.7446 & 2.5777 \\
\hline \multirow[t]{4}{*}{ PGII ( $\mu \mathrm{g} / \mathrm{L})$} & $50-59$ years & 134 & 11.7030 & 10.3706 & 0.8959 \\
\hline & $60-69$ years & 120 & 12.1780 & 9.4390 & 0.8617 \\
\hline & $70+$ years & 34 & 12.9740 & 9.4896 & 1.6275 \\
\hline & Total & 288 & 12.0480 & 9.8640 & $0-0581$ \\
\hline \multirow[t]{4}{*}{ PGI/PGII ratio } & $50-59$ years & 134 & 10.0840 & 4.4246 & 0.3822 \\
\hline & $60-69$ years & 120 & 9.6950 & 4.6364 & 0.4232 \\
\hline & $70+$ years & 34 & 7.6100 & 3.7772 & 0.6478 \\
\hline & Total & 288 & 9.6300 & 4.4953 & 0.2849 \\
\hline \multirow{4}{*}{$\begin{array}{l}\text { Helicobacter } \\
\text { pylori Ab titre } \\
\text { (EIU) }\end{array}$} & $50-59$ years & 134 & 72.9270 & 46.5802 & 4.0239 \\
\hline & $60-69$ years & 120 & 80.8910 & 42.3679 & 3.8676 \\
\hline & $70+$ years & 34 & 91.2500 & 51.0485 & 8.7547 \\
\hline & Total & 288 & 78.4090 & 45.6677 & 2.2610 \\
\hline
\end{tabular}

G 17 = Gastrin 17; PGI = Prostaglandin I; PGII = Prostaglandin II 
TABLE 3. Gastropanel data for men and women

\begin{tabular}{|c|c|c|c|c|}
\hline & $\mathbf{N}$ & Mean & Std. Deviaton & Std. error \\
\hline \multirow[t]{3}{*}{ G 17 basal (pmol/L) } & W 109 & 16.4890 & 94.3688 & 9.0389 \\
\hline & M 127 & 7.9550 & 9.8272 & 0.8720 \\
\hline & T 236 & 11.8670 & 64.5188 & 4.1998 \\
\hline \multirow[t]{3}{*}{ PGI ( $\mu \mathrm{g} / \mathrm{L})$} & W 134 & 95.4210 & 44.0496 & 3.8053 \\
\hline & M 154 & 96.1380 & 43.6186 & 3.5149 \\
\hline & T 288 & 95.8050 & 43.7446 & 2.5777 \\
\hline \multirow[t]{3}{*}{ PGII $(\mu g / L)$} & W 134 & 13.1840 & 12.5659 & 1.0855 \\
\hline & M 154 & 11.0600 & 6.5683 & 0.5293 \\
\hline & T 288 & 12.0480 & 9.8640 & 0.5812 \\
\hline \multirow[t]{3}{*}{ PGI/PGII ratio } & W 134 & 9.4370 & 4.5881 & 0.3963 \\
\hline & M 154 & 9.7980 & 4.4210 & 0.3563 \\
\hline & T 288 & 9.6300 & 4.4953 & 0.2649 \\
\hline \multirow[t]{3}{*}{$\begin{array}{l}\text { Helicobacter pylori } \\
\text { Ab titre (EIU) }\end{array}$} & W 134 & 75.8700 & 47.1760 & 4.0754 \\
\hline & M 154 & 80.6170 & 44.3496 & 3.5738 \\
\hline & Т 288 & 78.4090 & 45.6677 & 2.6910 \\
\hline
\end{tabular}

G 17 = Gastrin 17; PGI = Prostaglandin I; PGII = Prostaglandin II
Combined accuracy for preneoplastic lesions in Gastropanel positive patients was $87.5 \%$.

Incidence rate of OLGIM/OLGA $\geq 1$ as criteria for atrophic gastritis in our study population was $7.3 \%$ (6.9\% for OLGIM and $6.6 \%$ for OLGA). We found 3 patients with CAG, 1 patient with AAG, and 17 patients with chronic atrophic pangastritis.

\section{Discussion}

In countries with high incidence rate of gastric cancer, national programs for secondary prevention and early gastric cancer detection have been put in place. In Japan, they use barium double-contrast radiography combined with endoscopy from 1960 , or direct gastroscopy in recent years. A total of 3,000 to 6,000 gastric cancer cases are detected annually. Among these cases, EGC (early gastric cancer) accounts for approximately $50 \%$ to $70 \%$. An estimated $50 \%$ of patients undergo resection or delamination of the gastric mucosa through endoscopy. ${ }^{23}$ In Korea, the direct upper gastrointestinal series, or endoscopic detection (or a combination) was adopted above the age of 40 as a way of gastric cancer screening and takes place every two years. Owing to the early diagnosis and treatment of gastric cancer, the 5-year survival rate of gastric cancer in Korea gradually increased from $40 \%$ during the 1990 s to more than $60 \%$ at the beginning of this century. ${ }^{24}$

To improve the compliance and to reduce the costs, serologic biopsy has been introduced in Asia. It allows selection of patients with higher risk for preneoplastic gastric changes and reduces the endoscopic workload and costs. Since the 1990s, the detection of serum PG combined with endoscopy has been conducted in Japan to screen for gastric cancer. Miki et al. reported that among 101,892 Japanese, 125 cases of gastric cancer were detected using serum PG and endoscopy, with a detection rate for cancer of $0.12 \%$. Among these cases, EGC accounted for $80 \%$ (25). This combined approach is now in place also in some regions of China. ${ }^{13,14,28,29}$

Gastric cancer incidence is the most prevalent in certain countries of East Asia, but Eastern and Central parts of Europe are on the second place regarding incidence of gastric cancer. In Slovenia, average gastric cancer incidence is $23.4 / 100,000$ with $-0.3 \%$ change in incidence per year in the last 10 years. ${ }^{2}$

H. pylori is the main carcinogen in gastric carcinogenesis responsible for $89 \%$ of all gastric cancers. ${ }^{3}$ Slovenian Association for Gastroenterology 
and Hepatology Recommendations for H. pylori diagnosis and treatment clearly stated that we should start with primary prevention in a way of screen and treat for $\mathrm{H}$. pylori in population between 20 and 30 years before preneoplastic conditions develop. ${ }^{28}$ At the moment, we practice opportunistic prevention for our elderly population according to MAPS (Management of precancerous conditions and lesions in the stomach) recommendations. ${ }^{4,7}$

The prevalence of preneoplasic changes in the stomach is $2 \%-5 \%$ in the developed world ${ }^{29}$, but it is much higher in the developing world. The prevalence of preneoplastic lesions in St Petersburg study was $10.8 \%{ }^{30}$, while in our study it was $7.3 \%$. The real prevalence is probably slightly higher, because we know that sensitivity of Gastropanel is $70.2 \%$ for CAG. Gastropanel missed some, especially early preneoplastic stages, so absolute numbers of preneoplastic changes in the population are higher. In some well conducted European studies, the sensitivity and specificity of the serologic biopsy to diagnose normal stomach mucosa in the population-based sample of the 1,000 subjects were $89 \%$ (95\% CI 86-92\%) and 92\% (90-95\%), respectively. ${ }^{31}$

Gastropanel software analysis found one patient with AAG and 15 patients with CAG. According to definite hystopathologic analysis, 1 patient had AAG, 3 CAG, and all the other Chronic atrophic pangastritis. ${ }^{17}$ In our opinion, accuracy of Gastropanel for any Chronic atrophic gastritis is good, but this test is not very accurate in distinguishing between fenotipic chronic atrophic gastritis subtypes. The problem partially lies in specificity of G 17 as a marker of antrum atropy. G 17 can be low in patients with antral atrophy, but also in case of high gastric acid output. On the other hand, high G 17 is present in patients with corpus atrophy as well as in patients on PPIs. ${ }^{11}$

Our study was not designed in a way to be able to calculate sensitivity and specificity of Gastropanel for chronic atrophic changes in the stomach. On the other hand, the majority of patients tested positive for preneoplastic conditions in the stomach by gastropanel were also positive with histology. In our study, the accuracy of Gastropanel for detection of preneoplastic condition in the stomach was $87.5 \%$. This makes Gastropanel a suitable first step test in secondary prevention of gastric cancer; positive patients can then be sent to endoscopy.

Worldwide, the age-specific incidence of gastric cancer of intestinal type is approximately twice as high in males as in females. We did not find statis-
TABLE 4. Histologic phenotypes of gastric mucosa according to Gastropanel results

\begin{tabular}{lcccc}
\hline & Frequency & Percent & Valid percent & $\begin{array}{c}\text { Cumulative } \\
\text { percent }\end{array}$ \\
\hline Normal panel & 73.00 & 25.30 & 25.30 & 25.30 \\
HP gastritis & 199.00 & 69.10 & 69.10 & 94.40 \\
AGA & 1.00 & 0.30 & 0.30 & 94.80 \\
AGC & 15.00 & 5.20 & 5.20 & 100.00 \\
Total & 288 & 100 & 100 & \\
\hline
\end{tabular}

$\mathrm{AGA}=$ Atrophic gastritis of antrum; $\mathrm{AGC}=$ Atrophic gastritis of corpus

TABLE 5. Age Group H. pylori positive vs. negative

\begin{tabular}{|c|c|c|c|c|}
\hline & \multirow{2}{*}{ Age Group } & \multicolumn{2}{|c|}{ Hp positive vs negative } & \multirow{2}{*}{ Total } \\
\hline & & $\mathrm{HP+}$ & Hp- & \\
\hline \multirow{2}{*}{$50-59$} & Count & 94 & 40 & 134 \\
\hline & \% within Age Group & $70.1 \%$ & $29.9 \%$ & $100.0 \%$ \\
\hline \multirow{2}{*}{$60-69$} & Count & 96 & 24 & 120 \\
\hline & $\%$ within Age Group & $80,0 \%$ & $20.0 \%$ & $100.0 \%$ \\
\hline \multirow{2}{*}{$70+$} & Count & 29 & 5 & 34 \\
\hline & $\%$ within Age Group & $85.3 \%$ & $14.7 \%$ & $100.0 \%$ \\
\hline \multirow{2}{*}{ Total } & Count & 219 & 69 & 288 \\
\hline & \% within Age Group & $76.0 \%$ & $24.0 \%$ & $100.0 \%$ \\
\hline
\end{tabular}

tically significant difference in $\mathrm{H}$. pylori infection rate in our study, neither in preneoplastic changes of stomach mucosa between men and women. There are evidences that this difference in gastric cancer incidence can be caused by hormonal influences. $^{32,33}$

The incidence of gastric cancer increases exponentially with age. However, in multivariate analyses, age is not an independent risk factor for gastric cancer, it is only a surrogate marker for $\mathrm{H}$. pylori infection rate which is a birth cohort effect. ${ }^{34,34} \mathrm{We}$ found lower PGI and PGI/PGII ratio in older age groups. We also found that values of PGI and the PGI/PGII ratio were lover in the higher stage of OLGIM, what has also been previously reported. ${ }^{36}$

The secondary objective of the study was to determine the prevalence of $\mathrm{H}$. pylori infection in the age group from 50 to 74 years. Gubina et al. published H. pylori epidemiologic study in 2005. ${ }^{37}$ The average prevalence of $\mathrm{H}$. pylori infection in Slovenia was $25.1 \%$, while the highest prevalence rate was $54 \%$ in the age group $>60$ years. We were surprised that in our study $\mathrm{H}$. pylori seropositivity was $76 \%$ and significantly increasing with age. In our epidemiologic study ${ }^{37}$, number of patients 
older than 60 years was low (76 participants), what can represent a selection bias to the study and partially explain lower H. pylori seropositivity in older population.

In five of those patients with preneoplastic lesions, H. pylori was negative. This was found also in other studies. ${ }^{17,25}$ When preneoplastic changes are diffused, H. pylori could not persist in the stomach anymore, but this does not prove that those patients were not infected previously in their lives.

This high H. pylori prevalence in our study population is comparable to the prevalence of $\mathrm{H}$. pylori in St Petersburg study (76.7\%) and in Astana study $(76.5 \%)^{38}$, albeit their population was younger than in our study. The high prevalence of $\mathrm{H}$. pylori in Slovenia goes in parallel with medium high gastric cancer prevalence rate and with predictions that our prevalence of gastric cancer will stay high in the future. ${ }^{2}$ This prediction speaks for itself that a program for secondary gastric cancer should be put in place in Slovenia. The most feasible program would be a two-step program with serologic gastric biopsy and gastroscopy for those tested positive.

\section{Conclusions}

Gastropanel test has proved to be a reliable noninvasive test for advanced gastric preneoplastic lesions that can select patients for further gastroscopy and biopsy in a National secondary gastric cancer prevention program. H. pylori prevalence rate in the age group $50-74$ is with $76 \%$ still very high.

\section{Acknowledgments}

Authors would like to thank prof Kari Syrjänen, Department of Clinical Research, Biohit Oyj, Helsinki, Finland for his support in the analysis of our results using the GastroSoft ${ }^{\circledR}$ (Biohit Oyj) interpretation software and statistical analysis.

Grants received from Biohit Ojy, Helsinki, Finland; Slovenian Association for Gastroenterology and Hepatology.

\section{References}

1. Ferlay J, Soerjomataram I, Dikshit R, Eser S, Mathers C,Rebelo M. Cance incidence and mortality worldwide: sources, methods and major patterns in GLOBOCAN 2012. Int J Cancer 2015; 136: E359-386. doi: 10.1002/ijc.29210
2. Zadnik V, Primic Zakelj M, Lokar K, Jarm K, Ivanus U, Zagar T. Cancer burden in Slovenia with the time trends analysis. Radiol Oncol 2018; 52(1): 7-13.; 51: 47-55. doi: 10.1515/raon-2017-0008

3. IARC/WHO. Helicobacter pylori eradication as a strategy for preventing gastric cancer. International Agency for Research on Cancer/ World Health Organisation; 2014. [citated 2017 Avg 15]. Available at http://www.iarc.fr/ en/publications/pdfs-online/wrk8/ or www.iarc.fr/en/ publications/pdfsonline/wrk8/. ISBN 978-92-832-2454-9

4. Malfertheiner P, Megraud F, O 'Morain CA, Gisbert JP, Kuipers EJ, Axon AT, et al. Management of Helicobacter pylori infection - the Maastricht V/Florence Consensus Report. Gut 2017; 66: 6-30. doi: 10.1136/gutjnl-2012-302084

5. Nakajima S. Gastric cancer screening in Japan, now and tomorrow. Nihon Rinsho 2012; 70: 1686-93. doi: 10.1007/s101200200000

6. Choi IJ. Screening and surveillance of gastric cancer. Korean J Gastroenterol 2007; 49: 15-22. doi: 10.4166/kjg.2009.54.2.67

7. Dinis-Ribeiro $M$, Areia $M$, de Vries AC, Marcos-Pinto R, Monteiro-Soares $\mathrm{M}, \mathrm{O}$ Connor $\mathrm{A}$, et al. Management of precancerous conditions and lesions in the stomach (MAPS): guideline from the European Society of Gastrointestinal Endoscopy (ESGE), European Helicobacter Study Group (EHSG), European Society of Pathology (ESP), and the Sociedade Portuguesa de Endoscopia Digestiva (SPED). Endoscopy 2012; 44: 74-94. doi: 10.1055/s0031-1291491

8. Tepeš B. Kavalar R. [Gastric cancer, screening possibilities and proposals for endoscopic and histologic follow-up of premalignant gastric lesions]. [Slovenian]. Zdrav Vestn 2010; 79: 366-74. doi: https://doi.org/10.6016/290

9. Yuan Y. A survey and evaluation of population-based screening for gastric cancer. Cancer Biol Med 2013; 10: 72-80. doi: 10.7497/j. issn.2095-3941.2013.02.002

10. Uemura N, Okamoto S, Yamamoto S, Matsumura N, Yamaguchi S, Yamakido $\mathrm{M}$, et al. Helicobacter pylori infection and the development of gastric cancer. N Engl J Med 2001; 345: 784-9. doi: 10.1056/NEJMoa001999

11. Syrjänen K. A Panel of Serum Biomarkers (GastroPanel ${ }^{\circ}$ ) in Non-invasive diagnosis of atrophic gastritis. Systematic review and meta-analysis. Anticancer Res 2016; 36: 5133-44. doi: 10.21873/anticanres.11083

12. Matsushima M, Miki K, Ichinose M, Kakei N, Yahagi N, Suzuki T, et al. The clinical application of the serum pepsinogen I and II levels as a mass screening method for gastric cancer. In: Takahashi K, editor. Aspartic proteinases: advances in experimental medicine and biology. New York: Plenum Press; 1995. p. 139-43.

13. Screening, early detection and treatment of cancer in China. Dong ZW, editor. Beijing: People's Medical Publishing House; 2009.

14. Early detection and treatment of cancer committee. Technical solution on early detection and treatment of cancer in China. Beijing: People's Medical Publishing House; 2011.

15. Sipponen P. Biomarkers in clinical practice: a tool to find subjects at high risk for stomach cancer. A personal view. Adv Med Sci 2006; 51: 51-3.

16. Väänänen $H$, Vauhkonen $M$, Helske $T$, Kääriäinen I, Rasmussen $M$, TunturiHihnala $\mathrm{H}$, et al. Nonendoscopic diagnosis of atrophic gastritis with a blood test. Correlation between gastric histology and serum levels of gastrin-17 and pepsinogen I: a multicentre study. Eur J Gastroenterol Hepatol 2003; 15: 885-91. doi: 10.1097/01.meg.0000059169.46867.01

17. Agréus L, Kuipers EJ, Kupcinskas L, Malfertheiner P, Di Mario F, Leja M, et al. Rationale in diagnosis and screening of atrophic gastritis with stomachspecific plasma biomarkers. Scand J Gastroenterol 2012; 47: 136-47. doi: 10.3109/00365521.2011.645501

18. Dixon M, Genta R, Yardley J, Correa P. Classification and grading of gastritis: the updated Sydney System. Am J Surg Pathol 1996; 10: 1161-81.

19. Rugge M, Meggio A, Pennelli G, Piscioli F, Giacomelli L, De Pretis G, et al. Gastritis staging in clinical practice: the OLGA staging system. Gut 2007; 56: 631-6. doi: 10.1136/gut.2006.106666

20. Capelle LG, de Vries AC, Haringsma J. The staging of gastritis with the OLGA system by using intestinal metaplasia as an accurate alternative for atrophic gastritis. Gastrointest Endosc 2010; 71: 1150-8. doi: 10.1016/j. gie.2009.12.029 
21. Tepeš B, Štabuc B. Slovenian society for gastroenterology and hepatology guidelines on the management of Helicobacter pylori infection. [Slovenian]. Zdrav Vestn 2011; 80: 647-56. doi: https://doi.org/10.6016/216

22. Syrjänen KJ, Sipponen P, Härkönen M, Peetsalu A and Korpela S. Accuracy of GastroPanel testing in detection of atrophic gastritis. Eur J Gastroenterol Hepatol 2015; 27: 102-4. doi: 10.1097/MEG.0000000000000215

23. Hamashima C, Shibuya D, Yamazaki H, Inoue K, Fukao A, Saito H, et al. The Japanese guidelines for gastric cancer screening. Jpn J Clin Oncol 2008; 38: 259-67. doi: 10.1093/jjco/hyn017

24. Jung KW, Park S, Kong HJ, Won YJ, Boo YK, Shin HR, et al. Cancer statistics in Korea: incidence, mortality and survival in 2006-2007. J Korean Med Sci 2010; 25: 1113-21. doi: 10.3346/jkms.2010.25.8.1113

25. Miki K, Ichinose M, Kawamura N, Matsushima M, Ahmad HB, Kimura M, et al. The significance of low serum pepsinogen levels to detect stomach cancer associated with extensive chronic gastritis in Japanese subjects. Jpn J Cancer Res 1989; 80: 111-4.

26. Zhang X, Xue L, Xing L, Wang J, Cui J, Mi J, et al. Low serum pepsinogen I and pepsinogen $\mathrm{I} / \mathrm{II}$ ratio and Helicobacter pylori infection are associated with increased risk of gastric cancer: 14year follow up result in a rural Chinese community. Int J Cancer 2012; 130: 1614-9. doi: 10.1002/ijc.26172

27. Yuan Y. Population-based gastric cancer screening in Zhuanghe, Liaoning, from 1997 to 2011. Zhonghua Zhong Liu Za Zhi 2012; 34: 538-42.

28. Tepeš B, Štabuc B. Slovenian Association for Gastroenterology and hepatology recommendations for the management of patients infected with Helicobacter pylori. Zdrav Vestn 2017 (in press).

29. Sipponen P, Graham DY. Importance of atrophic gastritis in diagnostics and prevention of gastric cancer: application of plasma biomarkers. Scand J Gastroenterol 2007; 42: 2-10. doi: 10.1080/00365520600863720

30. Roman LD, Lukyanchuk R, Sablin OA, Araslanova,El, Eklund C, Hendolin $\mathrm{P}$, et al. Prevalence of $\mathrm{H}$. pylorilnfection and atrophic gastritis in a population-based screening with serum biomarker panel (GastroPanel ${ }^{\circ}$ ) in St. Petersburg. Anticancer Res 2016; 36: 4129-38.

31. Storskrubb T, Aro P, Ronkainen J, Sipponen P, Nyhlin H, Talley NJ, et al. Serum biomarkers provide an accurate method for diagnosis of atrophic gastritis in a general population: the Kalixanda study. Scand J Gastroenterol 2008; 43: 1448-55. doi: 10.1080/00365520802273025

32. Sipponen $\mathrm{P}$, Correa P. Delayed rise in incidence of gastric cancer in females results in unique sex ratio (M/F) pattern: etiologic hypothesis. Gastric Cancer 2002; 5: 213-9. doi: 10.1007/s101200200037

33. Camargo MC, Goto Y, Zabaleta J, Morgan DR, Correa P, Rabkin CS. Sex hormones, hormonal interventions, and gastric cancer risk: a meta-analysis. Cancer Epidemiol Biomarkers Prev 2012; 21: 20-38. doi: 10.1158/10559965.EPI-11-0834

34. Sipponen P, Kekki M, Haapakoski J, Ihamäki T, Siurala M. Gastric cancer risk in chronic atrophic gastritis: statistical calculations of cross-sectional data. Int J Cancer 1985; 35: 173-7.

35. Roosendaal R, Kuipers EJ, Buitenwerf J, van Uffelen C, Meuwissen SG, van Kamp GJ, Vandenbroucke-Grauls CM. Helicobacter pylori and the birth cohort effect: evidence of a continuous decrease of infection rates in childhood. Am J Gastroenterol 1997; 92: 1480-2.

36. Väänänen $H$, Vauhkonen $M$, Helske $T$, Kääriäinen I, Rasmussen $M$, TunturiHihnala $\mathrm{H}$, et al. Nonendoscopic diagnosis of atrophic gastritis with a blood test. Correlation between gastric histology and serum levels of gastrin-17 and pepsinogen I: a multicentre study. Eur J Gastroenterol Hepatol 2003; 15: 885-91. doi: 10.1097/01.meg.0000059169.46867.01

37. Gubina M, Tepeš B, Vidmar G, Logar J, Wraber B, Poljanec J, Bricelj I, et al. The prevalence of Helicobacter pylori infection in Slovenia in 2005. Zdrav Vestn 2006; 75: 169-73.

38. Benberin V, Bektayeva R, Karabayeva R, Lebedev A, AkemeyevaK Paloheimo $\mathrm{L}$, et al. Prevalence of $\mathrm{H}$. pylori infection and atrophic gastritis among asymptomatic and dyspeptic adults in Kazakhstan. A Hospital-Based screening with a panel of serum biomarkers. Anticancer Res 2013; 33: 4595-602. 